\title{
A Review on Vehicle Health Monitoring System
}

\author{
Prof. Gaffar G. Momin | Aakanksha P. Purkar | Naresh S. Lokhande | Affanali A. Sayyad | Roshani R. \\ Chavhan
}

Mechanical Department, Pimpri-Chinchwad College of Engineering, Pune, Maharashtra, India

\section{To Cite this Article}

Prof. Gaffar G. Momin, Aakanksha P. Purkar, Naresh S. Lokhande, Affanali A. Sayyad and Roshani R. Chavhan, "A Review on Vehicle Health Monitoring System", International Journal for Modern Trends in Science and Technology, 6(9): 31-34, 2020.

\section{Article Info}

Received on 06-August-2020, Revised on 20-August-2020, Accepted on 25-August-2020, Published on 30-August-2020.

\section{ABSTRACT}

Vehicles need repair after a certain interval of time and if are not repaired at fixed intervals it can lead to accidents. The objective of the project is to continuously notify the owner about the air pressure of tire, quality of exhaust gas, wear of breaks, leakage of oil, the excessive heating of the engine or the blockage in fuel pipe, etc. Tire pressure monitoring sensor is used to get live tire pressure reading, gas sensor gives the readings of amount of carbon dioxide $\left(\mathrm{CO}_{2}\right)$, Nitrogen Oxides (NOx) etc. as amount and quality of exhaust gives the proper working condition of engine, flow sensor is used that senses the over flow of oil or leakage of oil, temperature sensor is employed in the engine that warns the owner about overheating of engine and a flow sensor is used that senses the proper flow of fuel in the pipe. All these sensor data is displayed on LCD display unit integrated with Arduino microcontroller.

Key words: Gas Sensor, Pressure Sensor, Flow Sensor, Temperature Sensor, Arduino.

\section{INTRODUCTION}

Many of today's vehicles include a wide range of systems and components that perform various operations while the vehicle is in use. Over time, repeated use of the vehicle may cause failure of individual systems or components. The failure of one component or system affects the overall performance of vehicle. For continuous better performance of vehicle, the best way isto carry out prescribed periodical inspection and repair in a prescribed way. It requires years of experience to inspect manually, thus the electronic vehicle health monitoring system is to be designed.

Monitoring systems are widespread in today's world. They are being extensively employed to monitor various parameters of a system or an entity. To name a few, we come across monitoring system to read the health of a patient; monitoring systems to control the data and voice communications and in many other fields. Monitoring systems are devices that automatically monitor measurements, collect the state data and store them for future purposes. The state data is collected at periodic intervals or at times when a certain parameter exceeds a limit which is unique to each parameter.

\section{LITERATURE REVIEW}

Das et al[1] proposed a vehicle accident and location monitoring system. Accident and the location of the vehicle are detected. By this system primary care is received as the accident information is available Anusha et al[2] implemented a system using LPC2148 and the system has features like storing in the database. The work includes GPS, GSM modules. Imteaj et al[3] developed an Android-based application that 
detects an accidental situation and sends an alert message to the nearest police station and medical care center. This application is organized with an external pressure sensor to extract the outward force of the vehicle body. Mayuresh et al[4] described a system that uses an open source platform and intended to monitor

and trace the location of a vehicle, the framework also checks fuel consumption, engine temperature and vehicle speed, GPS/GPRS/GSM modules are used for communication. Prasanth et al[5] designed and implemented a model that is based on Raspberry $\mathrm{Pi}$ and a smart phone android application. Manali et al[6] proposed a system that has an Android mobile assembled with GPS and GSM modules along with a processor that is setup in the vehicle. Harum et al[7] suggested a framework that is based on Raspberry pi that is connected to $3 \mathrm{G} / 4 \mathrm{G}$ dongle used as a Modem. Navod et al[8] designed and implemented vehicle tracking, vehicle monitoring, controlling and vehicle status.

\section{SYSTEM COMPONENTS}

A new and improved design for the vehicle monitoring system was developed based on the literature review and the problem identification. The required parameters for the design purpose are analyzed. The components required for the fabrication are selected. The specific types of sensors are used for their desired work and fitted at their desired position. The sensors used are wireless for convince of operator and extended life of sensors.

\begin{tabular}{|c|c|c|}
\hline $\begin{array}{l}\text { SR. } \\
\text { NO. }\end{array}$ & COMPONENT & FUNCTION \\
\hline 1 & $\begin{array}{l}\text { Microcontroll } \\
\text { er(Arduino) }\end{array}$ & $\begin{array}{l}\text { Integrating } \\
\text { input(sensors) with } \\
\text { output(LCD display). }\end{array}$ \\
\hline 2 & Flow sensor & $\begin{array}{l}\text { To indicate blockage or } \\
\text { leakage in fuel and oil } \\
\text { pipes. }\end{array}$ \\
\hline 3 & Gas sensor & $\begin{array}{l}\text { To get the amount of } \\
\text { gases in exhaust gas. }\end{array}$ \\
\hline 4 & $\begin{array}{l}\text { Pressure } \\
\text { sensor }\end{array}$ & To monitor tire pressure. \\
\hline 5 & $\begin{array}{l}\text { Temperature } \\
\text { sensor }\end{array}$ & $\begin{array}{l}\text { To monitor temperature } \\
\text { of engine, in case of } \\
\text { excessive heating. }\end{array}$ \\
\hline 6 & LCD display & $\begin{array}{l}\text { To display the input } \\
\text { readings taken by } \\
\text { sensors. }\end{array}$ \\
\hline
\end{tabular}

Table 3.0: - List of Components

\section{MICROCINTROLLER (ARDUINO)}

Microcontroller is a compressed micro computer manufactured to control the functions of embedded systems. The Microcontroller is used to control the devices and also collects the information from the sensors. A microcontroller is comprises components like - memory, peripherals and most importantly a processor. Arduino is an open-source electronics platform based on easy-to-use hardware and software. Arduino boards are able to read inputs like light on a sensor, a finger on a button, or a Twitter message and turn it into an output like activating a motor, turning on an LED, publishing something online.

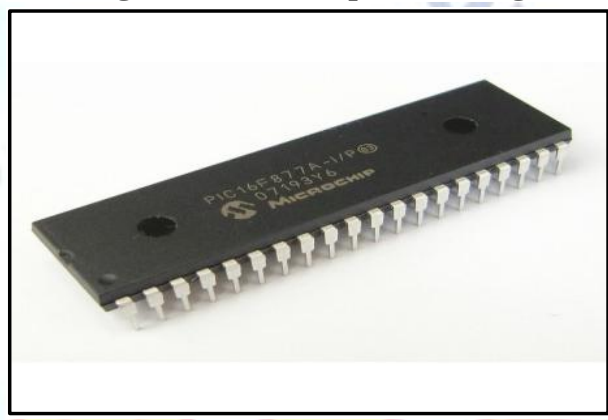

Fig-3.1 Microcontroller

\section{FLOW SENSOR}

Flow sensors are devices used for measuring the flow rate or quantity of a moving liquid or gas. The sensor works by measuring the cooling effect of the gas or liquid passing over a thin, heated wire. The higher the cooling effect, the higher will be the flow. In order to be accurate, the sensor needs to know the density of the liquid or gas, which is provided to the measurement system by the gas analysis data.

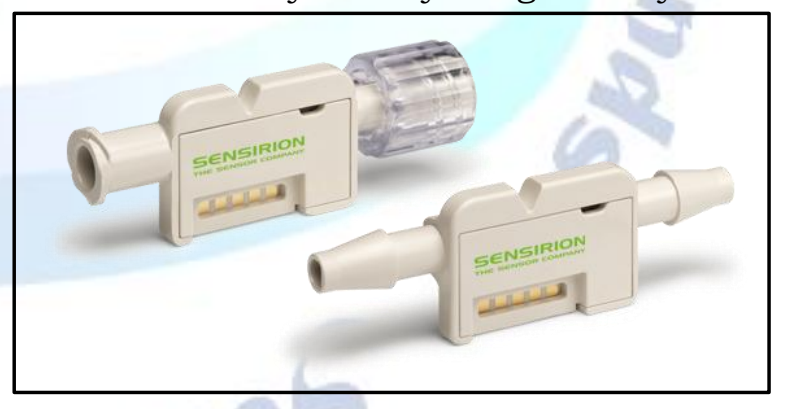

Fig-3.2 Flow Sensor

\section{GAS SENSOR}

A gas sensor is a device which detects the presence or concentration of gases in the atmosphere. Based on the concentration of the gas the sensor produces a corresponding potential difference by changing the resistance of the material inside the sensor, which can be measured as output voltage. Based on this voltage value the type and concentration of the gas can be estimated. 
The type of gas the sensor could detect depends on the sensing material present inside the sensor. Normally these sensors are available as modules with comparators. These comparators can be set for a particular threshold value of gas concentration. When the concentration of the gas exceeds this threshold the digital pin goes high. The analog pin can be used to measure the concentration of the gas.

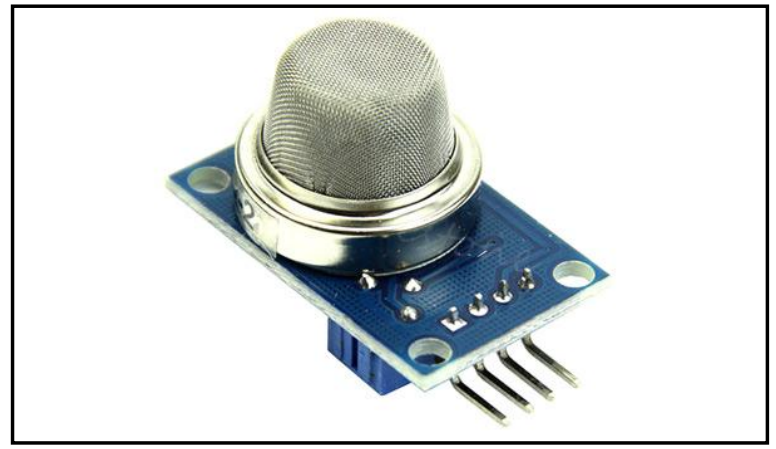

Fig-3.3 Gas Sensor

\section{PRESSURE SENSOR}

A tire-pressure sensor is a small programmable electronic device, located in the pressurized pocket made by a wheel and tire that constantly measures the air pressure inside the tire. The sensor transmits that information via low-frequency radio to the vehicle's onboard computer or to a corresponding display in the instrument cluster. It reads out in pounds per square inch (psi), and it illuminates an amber warning light to alert you if one or more tires are low on air.Tire-pressure sensors are integral to what is known as the Tire Pressure Monitoring System (TPMS).

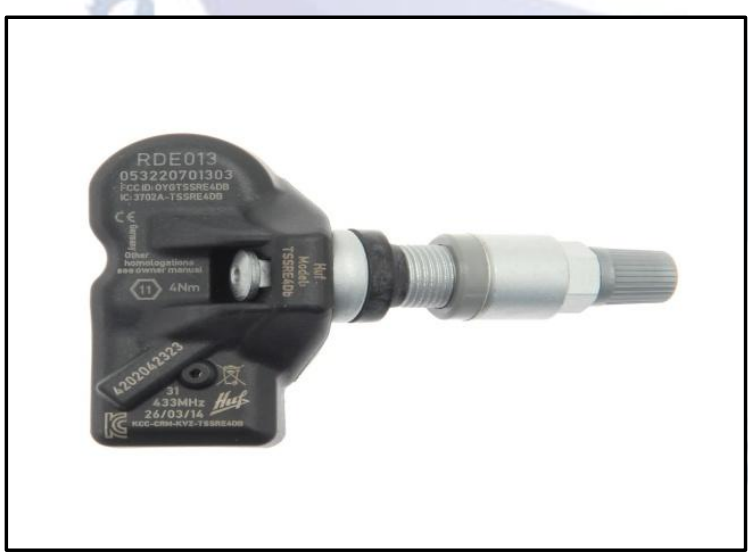

Fig.- 3.4 Tire Pressure Sensor

\section{TEMPERATURE SENSOR}

A temperature sensor is an electronic device that measures the temperature of its environment and converts the input data into electronic data to record, monitor, or signal temperature changes.
There are many different types of temperature sensors. Some temperature sensors require direct contact with the physical object that is being monitored (contact temperature sensors), while others indirectly measure the temperature of an object (non-contact temperature sensors).

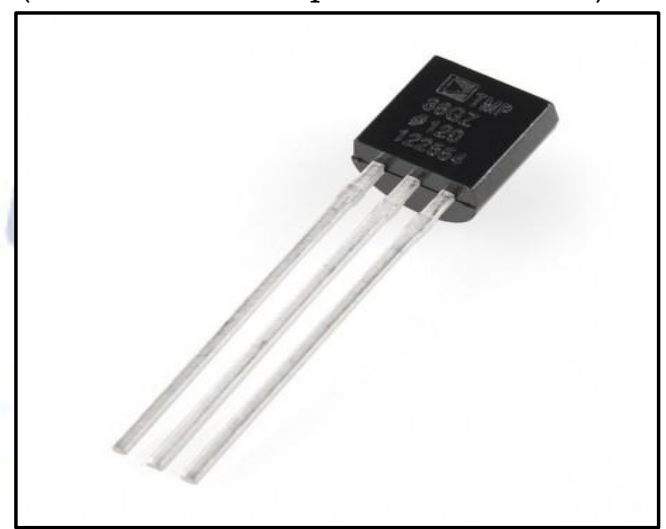

Fig,- 3.5 Temperature Sensor

\section{LCD DISPLAY}

LCD (Liquid Crystal Display) is a type of flat panel display which uses liquid crystals in its primary form of operation. The LCD display is used to display the information from the microcontroller. It displays the information from sensors.

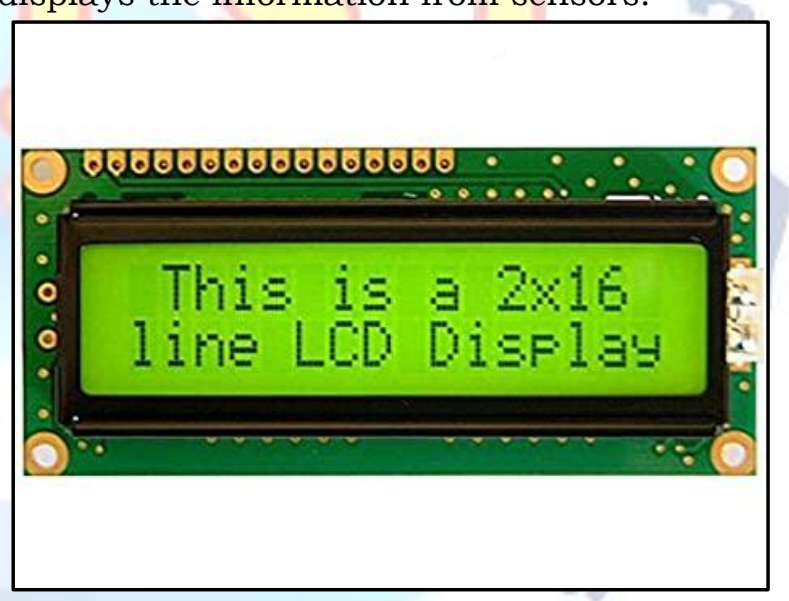

Fig. - 3.6 LCD Display

\section{LIMITATIONS}

1. The sensitivity range of the sensors used could confine the performance.

2. The connectors used such as Arduino or Raspberry Pi may lead to unsuccessful data transmission.

3. The LCD could sometimes display ambiguous results.

\section{WORKING}

The system is operated by a power supply from a battery. When the system gets operated, all the sensors get initialized. The flow sensors fitted at fuel supply and oil supply lines; any 
variation of flow rather than saved range will be indicated on LCD, lower flow rate will indicate blockage or leakage in pipes. The gas sensors are fitted at silencer which will give the readings of various gases, as sensor material is different for different gas, 2-3 sensors have to install.

The temperature sensor is installed at engine to monitor its temperature. The tire pressure sensors are installed at valves of tires which gives continuous readings of tire pressures. All this information is sent to the microcontroller and then LCD connected to microcontroller displaysall the information one by one at every 5 seconds.

\section{CONCLUSION}

The vehicle health monitoring system provides proper information about all basic parameters that affects or indicates the performance of vehicle. This continues information will lead to early indication of damage and we can pre diagnose the future fault leading to better performance of vehicle. As well as this system will provide correct information to owner so that during servicing of vehicles the service centers cannot give

wrong information and ask one for extra money. Vehicle health monitoring system will allow you to inspect your vehicle though you are beginner or not skilled in inspecting.

\section{REFERENCES}

[1] Manali Shilimkar "Survey Paper on Vehicle Tracking System using GPS and Android", International Journal of Advanced Research in Computer Engineering \& Technology (IJARCET) Volume 3 Issue 11, November 2014

[2] A. Anusha "Vehicle Tracking and Monitoring System to Enhance the Safety and Security Driving Using IoT" 2017 International Conference on Recent Trends in Electrical, Electronics and Computing Technologies (ICRTEECT), July 2017

[3] Mayuresh Desai "Internet of Things based vehicle monitoring system" 2017 Fourteenth International Conference on Wireless and Optical Communications Networks (WOCN) IEEE, Feb 2017

[4] Navod "Vehicle Monitoring, controlling andtracking System by using android application",International Journal of Technical Research and Applications,Volume4,Isuue1

[5] Prasanth "Advanced vehicle monitoring and tracking system based on Raspberry Pi", 2015 IEEE 9th International Conference on Intelligent Systems and Control (ISCO).

[6] Harum "Vehicle Detection and Tracking System IoTbased",International Research Journal of Engineering and Technology (IRJET),Volume-5,Issue-8.

[7] Imteaj"Smart Vehicle Accident Detection and Alarming System Using a Smartphone", conference: 2015 International Conference on Computer and Information Engineering (ICCIE), November 2015
[8] Das "Vehicle accident prevent cum location and monitoring system", 2017 8th Annual Industrial Automation and Electromechanical Engineering Conference (IEMECON),August 2017

[9] R. VINETH "VEHICLE MONITORING SYSTEM", International Research Journal of Engineering and Technology (IRJET) e-ISSN: 2395-0056 Volume: 06 Issue:Mar 2019
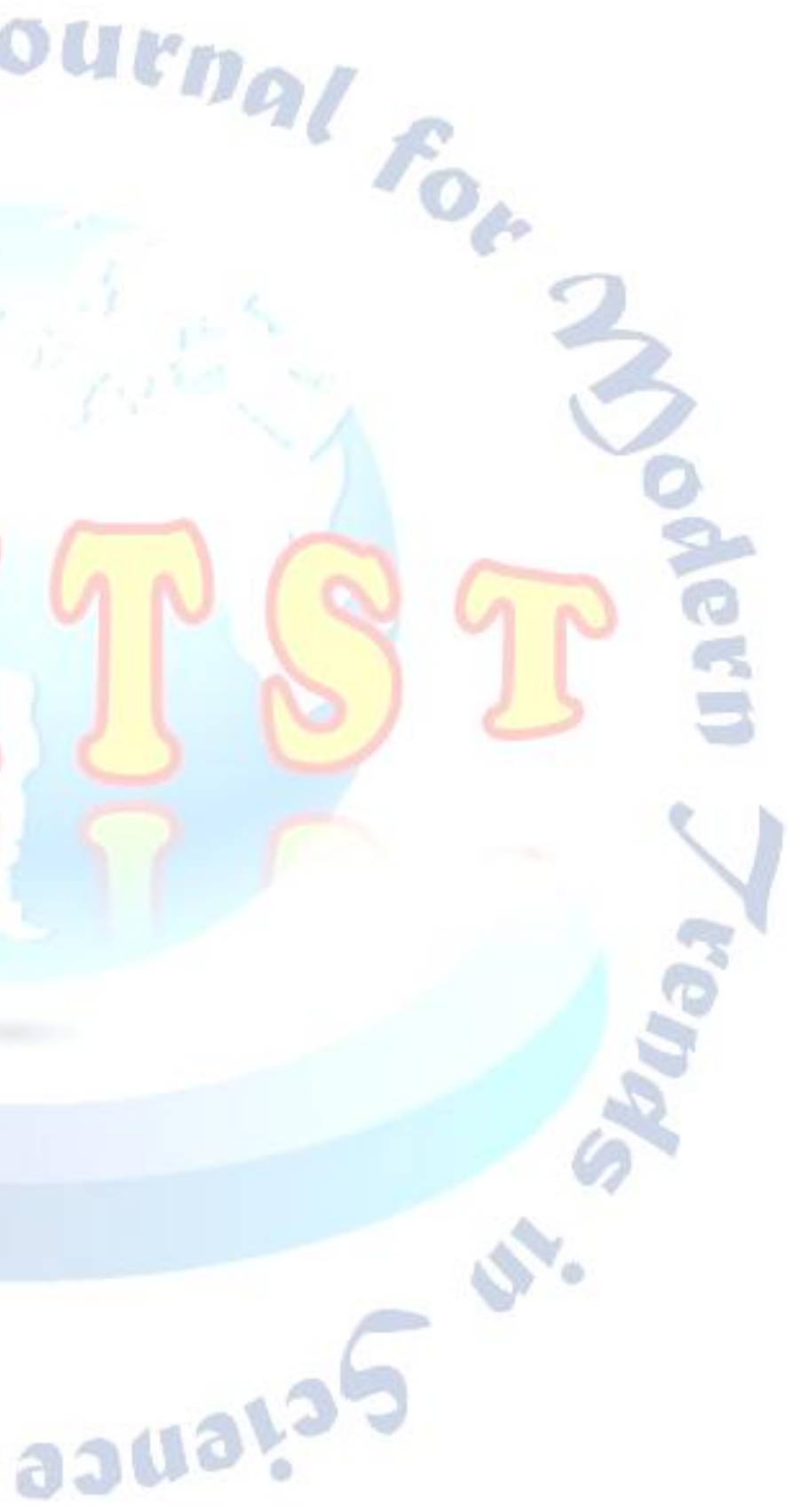